\title{
"They would not like it if men taught in the foundation phase": SGBs' perceptions of the employment of male FP teachers
}

\section{Obakeng Kagola}

Faculty of Education, Nelson Mandela University, Gqeberha, South Africa obakeng.kagola@mandela.ac.za https://orcid.org/0000-0002-9841-8696

\section{Mathabo Khau}

Faculty of Education,Nelson Mandela University, Gqeberha, South Africa

Mathabo.khau@mandela.ac.za

https://orcid.org/0000-0002-8933-0553

(Received: 18 March 2021; accepted: 23 September 2021)

\section{Abstract}

Efforts to recruit and retain men in the Foundation Phase (FP) teaching and learning have been made all over the world. In South Africa, School Governing Bodies (SGBs) are tasked with the responsibility of diversifying schooling by recommending to the Department of Basic Education (DBE) the employment of teachers in all educational phases. Two and a half decades after the dawn of democracy in South Africa, the teaching of children in the early years is still dominated by women. This study explores how SGBs in the Eastern Cape province of South Africa approach the employment of male teachers in FP. Using a qualitative research approach, we used a semi-structured focus group discussion to generate data with five SGB parent-component members. We analysed the data thematically and found that SGBs' employment of male FP teachers is based on societal constructions of gender over employment policy guidelines. The SGB members showed a lack of policy understanding and at times misinterpreted the policies. These findings have implications for education policymakers and teacher training institutions in facilitating the smooth incorporation of males into FP teaching.

Keywords: Foundation Phase (FP), male teachers, School Governing Bodies (SGBs), equitable employment 


\section{Introduction and background}

School governing bodies (SGBs) in South Africa are tasked with providing recommendations to the Department of Education (DoE) regarding the employment of teaching and administrative staff in the public schools they govern. This responsibility, among others, is premised on the South African government's objective of decentralising school governance, creating inclusive schooling communities, and promoting democratic values in schools (Xaba $\&$ Nhlapo, 2014; Department of Basic Education 2011a). However, two and a half decades after the adoption and implementation of the guiding policies that govern schools, including the South African Schools Act of 1996 (Department of Basic Education 2011b), the composition of foundation phase teachers remains highly dominated by females. In this educational phase, $78 \%$ of teachers are female (SNAP, 2015; Bhana, 2016).

The dominance of females in FP teaching is a global phenomenon, with countries like Ireland, Australia, and New Zealand, to name three, having come up with strategies and policies such as bursaries and awareness campaigns to motivate the inclusion of males in early childhood education (McCormack \& Brownhill, 2014). However, there has not been a significant increase in males joining this teaching phase because of institutionalised resistance towards men in early childhood education (Brownhill, 2015). Researchers in gender and early childhood education have argued that the high number of female teachers in the FP is premised on the narrative that associates nurturing and care work with women (Mashiya et al., 2015; Moosa \& Bhana, 2018; Msiza, 2019; Warin, 2019; Xu \& Waniganayake, 2017).

Bhana and Moosa (2016) posited that pre-service male teachers registered for other teacher training programmes in one South African university did not regard FP teaching as suitable for themselves given its perceived low status. Bhana (2016) and Ratele (2015) argued that the apartheid and colonial history of South Africa contributed to the gendered division of labour in assigning important status to the work done by males and devaluing that done by females. This practice categorised work such as the teaching of young children, nursing, and hairdressing, to mention only three, as being suitable for females, not males (Morrell, 2019). Throughout South African history, privilege, dominance, and leadership roles have always characterised men in general, and, have led, in particular, to the construction of hegemonic masculinities in this country (Bhana, 2016; Ratele et al., 2012).

Under the current democratic regime, the tables have turned, and females are gradually crossing the gender border in taking up employment in previously male-dominated fields (Moorosi, 2010; Moosa \& Bhana, 2018). Mashiya et al., (2015) and Moosa and Bhana (2017) have argued that this is progress towards gender equality in South Africa. The opposite, however, in relation to men seeking work in previously female-dominated fields, is not the case. In support of this Msiza (2019) indicated that males seeking employment in such professions like FP teaching is not easy since they are often policed and perceived to have ulterior motives such as wanting to engage in paedophiliac behaviour (Mashiya et al., 2015; 
Moosa \& Bhana, 2018; Msiza, 2019). The male teachers' masculinity is also questioned and at times they are belittled (Kagola \& Khau, 2020; Msiza, 2020).

These studies capture something of the potential creation of an inclusive schooling system that involves men in early childhood education. However, these studies do not entirely account for the low recruitment of males in FP, considering that the mandate of SGBs is to employ teachers and to promote diversity, gender equality, and equal opportunities for all. In South Africa, there is insufficient research on how SGBs handle the employment of male teachers in FP. The phenomenon of male FP teachers and how gatekeepers such as SGBs handle their employment in the Eastern Cape Province is under-researched.

The Eastern Cape is a province dominated by the amaXhosa ethnic group that has specific cultural values and norms that have an impact on the construction and performance of masculinities (Mfecane, 2016; Tenge, 2006). Some of the dominant cultural practices include Ulwaluko, the taking of the boy child through the rite of passage into manhood (Ntombana, 2011). Morrell et al. (2012) have argued that cultural norms influence the gender norms in society by associating hegemonic masculinities with oppressive attitudes and practices. In similar vein, Jewkes et al. (2015) have argued that while men benefit from society's "patriarchal dividend" (Connell, 2009, p. 142), they have a choice regarding whether to take up or resist their oppressive positions against women and other men. Thus, men who choose to teach in FP are exercising their agency in challenging such constructions of hegemonic masculinity.

SGBs, as members of a specific culture and of a gendered society, are socialised into a particular patriarchal gender order so it is reasonable that they may approach their governance role based on this patriarchal socialisation. This might well have an impact on the recruitment and retainment of male teachers in FP in the Eastern Cape. To counter such socialisation, Jewkes et al. (2015) have explained that masculinity is not inherently oppressive so gender interventions must focus on changing the patriarchal gender order that positions men as oppressive and in this way, reconfigure masculine ideals. In this paper, therefore, we explore how SGBs in the Eastern Cape province exercise their responsibility of recommending employment of male FP teachers in a bid to reconfigure masculine ideals and practise social justice and diversity in FP teaching.

\section{School governance: A South African perspective}

The South African Schools Act (SASA) of 1996 (Department of Basic Education, 2011b) is a guiding tool for school governors and their legitimisation (Mncube et al., 2011). SASA is a tool that guides school management and governance in the processes of redressing the injustices of the past (Mncube, 2007; Xaba \& Nhlapo, 2014). SASA requires that parents form the majority on SGBs in primary schools to enable parental agency in addressing issues of social justice in a country fraught with racism, oppression, and gender discrimination (Bush \& Glover, 2016; Mncube, 2007). Consequently, parents occupy strategic positions 
such as chairperson, secretary, and treasurer in the school governance committee (Department of Basic Education, 2011; Mncube, 2007).

The primary task of SGBs is the equitable appointment of staff to redress the injustices of the past (Mncube et al., 2011; Department of Basic Education, 2011b). Despite the good intentions of SASA (Mncube et al., 2011), many challenges hamper its successful implementation. These challenges include the low educational levels of most of the parentcomponent members of SGBs, power relations in general, and nepotism in particular when the school is employing staff throughout the different educational bands (Bush \& Glover, 2016; Smit \& Oosthuizen, 2011). Furthermore, contextual factors surrounding the schools such as poverty and poor health services, along with, as mentioned above, the cultural norms and values held by communities in which SGB members are located, play a huge role in decision making regarding school governance (Moorosi, 2010; Xaba \& Nhlapo, 2014). In spite of these challenges, SGBs have been successful in other areas such as changing the language policy and including differently abled learners in primary schools (Basson \& Mestry, 2019; Bush and Glover, 2016; Mutekwe, 2020) so we see that change is possible.

Moorosi (2010) found that lack of support from school governors was a significant challenge for women in the area of male-dominated principalship. She argued for a stronger research focus on leadership, gender, and social change to deconstruct patriarchal norms in societies. To address these challenges and achieve equality in education, Moorosi (2010) and Van Wyk (2004) highlighted the need for courageous conversations with community members aimed at dismantling traditional stereotypes. This could assist SGBs to operate within the constitutional framework of South Africa (Mncube \& Du Plessis, 2011) and thus bring about change in FP teaching. In this paper we contribute to the ongoing conversation and conscientisation of SGBs about their role in the diversification of schools in general and FP teaching in particular through the employment of teachers without prejudice based on their sex or gender.

\section{A feminist poststructural perspective}

Put briefly, poststructural feminism centres on the notion of socially created realities that form linkages between oppression on the one hand, and individual and societal practices on the other (Lather, 1991). St. Pierre (2000) noted that post-structural feminism is based on the belief that people can be active agents in creating their own realities instead of being passive victims of social reproduction. This theory is based on the situatedness of individual experiences, hence the importance of acknowledging that individual experiences are shaped through language, power, and social structures that can produce opposing ways of meaningmaking (Jackson, 2001). When people interact with different discursive fields, they may create deep seated values and meanings that bind them to the norms existing in their particular society.

Poststructural feminist theorists explore the production, function, regulation, and place of discourse in society (Weedon, 1997). They employ radical deconstruction to disrupt 
normative discourses surrounding patriarchy and gender roles (Crawley \& Broad, 2008; Davies \& Gannon, 2005; Osgood, 2012). Discourses, being concepts that work towards producing realities in different contexts, can create an environment that is both oppressive and emancipatory to the marginalised (Blaise, 2005; Foucault, 1980). Feminist poststructural researchers believe that we can move beyond what is documented, known, and understood about dominant discourses in a specific context, such as feminised FP teaching (Blaise, 2005; Osgood, 2012; Weedon, 1997). All feminists aim to multiply the possibilities and demystify methods of thinking that lead to positioning females or males in societies or in particular careers (Davies \& Gannon, 2005; Osgood, 2012). The employment of feminist ideals could raise awareness in SGBs on the gendered discourse that surrounds FP teaching.

In this study, participants explored how their role as governors can contribute to the feminisation of FP teaching. Participants also examined how, given the power of existing dominant discourses in their societies (see Barrett, 2005), their subjectivity influenced their decision-making. Mayeza (2018) has explained that people navigate their subjectivity through aligning with dominant discourses in their individual context. And this might well be the case of the participants in this study because they come from communities that have a patriarchal gender order that regulates the constructions of femininity and masculinity. Butler (1990) noted that the performance of gender roles and people's subjectivity (re)produces certain discourses that normalise and regulate the gendered binaries of being female and male, such as, in this case, the assumption that FP teaching is women's work. Bhana (2016) suggested that such discourses are perpetuated by those in power to sustain the particular gender order that dissociates men from care professions such as FP teaching. Feminism, particularly from a poststructuralist perspective, helps us to understand the dynamics of gender socialisation as implicated in the SGB's recommendations regarding the employment of teachers in FP.

\section{Methodology}

This paper is based on a bigger qualitative study in line with Creswell and Creswell (2017). We used participatory visual methodologies such as the creation of collages (see Kagola \& Khau, 2020), and participatory methods such as semi-structured focus group conversations to enable SGB parent-component members to share their understandings and experiences in the employment of male FP teachers. In this article, we discuss only the semi-structured focus group conversations. Qualitative researchers have explained that this approach assists participants to share their lived experiences and personal interpretations of a phenomenon and reflect on their opinions regarding this in a particular context (De Vos et al., 2014). The critical paradigm we used to anchor the study aims to disrupt the unjust norms in this particular society and work towards the conscientisation of the SGB communities regarding this particular phenomenon (see Taylor \& Medina, 2011). In this paper, we focus on the data generated during focus group conversations between the participants and the facilitator. 
This study was conducted in the Nelson Mandela Bay Metropolitan (NMBM) district of the Eastern Cape Province in South Africa ${ }^{1}$ because of the "low statistics on the appointment and retainment of male FP teachers" (Bhana, 2016, p. 49), and because the field is relatively under-studied. It was therefore imperative to explore how male FP teachers are perceived when they are being considered for teaching positions in a province with deep-seated cultural practices related to masculinity.

Five primary schools in the area of Zwide and Missionvale in the Nelson Mandela metropole were invited to participate in the study. However, only two schools responded to the invitation. Parent-component members were purposively selected because they comprise the majority and hold influential positions in the SGBs of primary schools (Department of Basic Education 2011a). Consent forms were read and explained to the participants who then agreed to participate in the study, and permission to record the focus group conversation was obtained in writing. Pseudonyms were used throughout the study to ensure participants' anonymity.

The participants from Luvoyo Primary were Ngezile, a 59-year-old male, serving his second term as the chairperson and Nomi, a 45-year-old female, serving her first term as treasurer of the SGB. From Siviwe Primary the participants were Nyembezi, 59, who was serving his second term as chairperson, Yolisa, 37, and Nozuko, 49, two women who were serving the SGB as deputy chairperson and deputy secretary respectively. Participants were encouraged to communicate in their language of choice to help generate rich data, and they therefore code-switched between isiXhosa and English. The following anchoring question was asked during the focus group session:

What are your views on the employment of males to teach in Foundation Phase?

Recordings of the focus group conversations were transcribed and translated. We then thematically analysed the data to identify broad themes that surfaced in the focus group conversations (see De Vos et al., 2014). We then coded the themes and identified the most descriptive categories, with related themes merged into these categories (see Creswell, 2005; De Vos et al., 2014). To produce quality data and to ensure the accuracy of the findings, we went back to the data generated in isiXhosa and regularly checked consistency in data and themes. Member checking was done with participants in instances where clarity and confirmation of details were required to maintain the integrity and trustworthiness of the study. In the next section, we discuss the major themes that emerged from the data.

\section{Findings and discussions}

Two themes emerged from the focus group conversation.

- Societal perceptions take precedence in school governance.

The study was approved by the Nelson Mandela University ethics committee (H18-EDU-ERE-015), and the Eastern Cape provincial Department of Education granted us permission to do this research in the province. 
- Teacher employment policy is not clearly understood.

\section{Societal perceptions take precedence in school governance}

In this section, we present the views of the SGB participants regarding the employment of male teachers in schools, based on societal constructions of gender roles, their lived experiences of serving in the SGB, and interactions with the communities that entrusted them with the power to govern their schools. SGB members were encouraged to talk about their experiences regarding the employment of male teachers in FP. Ngezile said,

My brother, I don't think parents in the school where I am the chairman will approve having a man in the foundation phase ... even the principal and myself I am not comfortable with it . . . as a man and the chairman of the SGB, I have seen these men . . . on Mondays, they are babalazed [hungover], they take advantage of these children.

Ngezile's comment indicates that he would not recommend the employment of males in FP based on what he recalls as his experience. Similarly, another man, Nyembezi, had a negative view of male employment in the area of FP teaching. He said,

No ... before we do anything at our school, we think about the people who voted for us, the other parents . . . would they like it if men taught in foundation phase? I don't think so . . . men used to work for their families my brother, and women take care of children. I don't think our community is ready for such change in our primary school.

Ngezile's and Nyembezi's comments highlight and uphold the power of dominant social discourses in their communities that devalue care work and consider it to be a low status option for men (see Bhana, 2016; Msiza, 2020). Socio-cultural norms maintain the belief that FP teaching is feminine work (Moosa \& Bhana, 2020; Msiza, 2019) and SGBs thus sustain the feminised discourse of FP as Pitsoe and Letseka (2013) have pointed out. They rationalise their decision because they believe that jobs related to authority and power are reserved for males while caring jobs are for fitting for females (Cameron et al., 1999; Cruickshank et al., 2018).

Msibi (2009) has pointed out that African men have been constructed as violent through colonial machinery and are viewed as having the proclivity to be readily rapist. Ngezile and Nyembezi align their arguments with this belief despite the requirements of education policies and constitutional guidelines. This perpetuates the exclusion of men from the caring professions like FP teaching. Ratele (2016) has argued that gender roles are socially constructed and cannot be divorced from the context in which they operate, so it is hardly surprising that Ngezile and Nyembezi see masculinity as being associated with violence and abuse and not with caregiving.

Researchers (see Bhana \& Moosa, 2016; Msiza, 2020; Ratele, 2016) have pointed out that this hegemonic construction of masculinity characterised by violence may contribute to toxic masculinities and the increasing rate of gender-based violence in South Africa. Interestingly, one could also interpret Ngezile's and Nyembezi's comments as deriving from their 
investment in that patriarchal dividend" (Connell, 2009, p. 142) discussed above. Nyembezi refers to men working and women taking care of children as if that which is done by females is not work. This, of course, undervalues the work done by women and constructs FP teaching as a profession that is not suitable for men (Moosa \& Bhana, 2017; Skelton, 2003).

That Nyembezi and Ngezile are both chairpersons in SGBs makes evident the predominance of men in decision-making positions. It is essential to note how Ngezile uses his position of authority to dissociate men with FP teaching by referring to only the negative facets of men as teachers in FP. Nozuko, the deputy secretary at Siviwe Primary, had similar views to Ngezile but was more open to possibilities of granting access to male teachers in FP teaching. She said,

For me it will be a difficult one ... how would that man look like? Because in that phase we need people that will care and raise our children well . . O Our children have high levels of respect for their fathers and uncles at home. They can't just approach them . . . children are scared of men they don't know. . . however, times have changed ... I think if they are qualified, we can give them a chance ...

It is difficult for Nozuko to imagine men teaching in FP. Her socialisation has taught her that men are ranked higher than women, and are not easily approachable, and this, in essence, normalises the fear of men felt by women and children. She has preconceived notions of how a man should be, and, to her, nurturing does not resonate with what she thinks of men. Bhana (2016) suggested that part of the issue that dissociates males from FP teaching is the perceived idea that children in FP are vulnerable and innocent. It is assumed that men cannot work with children in this educational phase because of the children's vulnerability.

Bhana (2016) and Ratele (2016), however, have pointed out that masculinities based on being aggressive and non-caring are social constructs and, therefore, can be reconstructed to see men as suitable mentors and teachers of children in FP learning. Men should be liberated from the toxic ideals of what a man is or should be (Ratele, 2016). Nozuko's view is aligned with Weedon's (1997) theorisation regarding the existence of hegemonic discourses that lead, in this case, to the perception of teaching FP as a feminine profession. However, she noted that qualified men should be given a chance and her acknowledgement of at least potential change is a starting point towards reconstructing the discourses that influence SGB members.

Nomi's view is similar to Nozuko's. She was, however, more critical in her thinking regarding their responsibility as SGB members. She explained,

Yes, I hear you all. But I think we have a responsibility to be fair and give everyone the opportunity to prove themselves ... I think in our school we as the SGB can recommend the man teacher if he has the right qualification and experience. We have the responsibility to represent the community. Yes Bhuti Nyembezi, but we also have the policies to implement ...

Yolisa shared the same standpoint as Nomi and said, 
Nomi has a point. My father was good with children and me for that matter ... I used to play with him and all that. I think it's a good idea to have a man teach in Foundation phase ... women have been good at working with children . . . but I think it's time we give men a chance to be fathers to fatherless children in schools especially boys. I see women working at EPWP (Expanded Public Works Programme) doing hard work installing pipes ... I don't see a problem with a man teaching foundation phase.

Pitsoe and Letseka (2013, p. 7) asserted that "once a discourse becomes 'normal' and 'natural,' it is difficult to think and act outside it . .." but Foucault (1980) argued that shifts in debunking historical thought do occur when people think of different ways to act and communicate. The advocacy of the three female participants for the inclusion of males in FP teaching makes this apparent. Additionally, Nomi and Yolisa reminded the other members of the employment policy and their responsibility to remain fair and promote social justice in schools, thus challenging Xaba and Nhlapo's (2014) assertion that most of the parentcomponent members have limited policy knowledge and hence get overruled in recommending staff for employment. Nomi's acknowledgement of the policy and how it should be adhered to in the interests of promoting democratic values and fairness in the employment of staff highlighted a shift in discourse. She said, "The SASA is a very clear policy that speaks about being fair and we must not discriminate."

Nomi, Nozuko, and Yolisa, being fair in their role of governance, advocate for granting opportunities to qualified and experienced FP male teachers. Yolisa, however, rationalises her approach to the employment of male FP teachers from an essentialist perspective that assumes that employing males in early childhood education could help with their being fathers to boys raised in female-headed families (Warin \& Adriany, 2017; Skelton, 2012; Xu \& Waniganayake, 2018). Warin and Adriany (2017) argued that the involvement of men in FP teaching should not be premised on a role of being substitute fathers to children raised in single parent families. This is because men are capable of teaching and caring for children without necessarily fathering them or acting as their fathers. Further, in support of the above researchers, Xu and Waniganayake (2018) stated that not all men who choose to be FP teachers may want to perform the fathering role. They suggest that children should experience the presence of both female and male teachers in their early years of learning.

\section{Teacher employment policy not clearly understood}

Another explanation of why SGB members in this study perceived FP teaching in gendered terms could be their possible lack of understanding of the policy. One of the primary responsibilities of the SGBs, as outlined in SASA (1996) is to ensure that all schools conform to the democratic values as stipulated in the constitution of the country. Despite this, Nyembezi, Nozuko, and Ngezile presented different explanations of how teachers are employed and how policy is interpreted and implemented in their schools. Nyembezi said, 
Education policy on SASA, they don't put male teachers, even when they advertised the post on the bulletin, they write there; but they make it there as a policy, we are looking for a female teacher for the foundation phase.

Nozuko said,

Bhuti Nyembezi we are the ones who should approve those bulletins. . who are they? I think but I am not sure. . . You are right ipolicy must change to include males.

Ngezile added,

Bhuti let me tell you this is my second time being in SGB. I have never seen or heard that the advertisement of foundation phase teacher is looking for a man, we always look for a woman ... I think it is somewhere in those policies.

Nyembezi and Ngezile stated that the policy is not clear on who should be employed in FP teaching, despite Nozuko's arguing for the inclusion of males in FP. They were unaware that the policy to which they referred advocated for a non-sexist approach in appointing teachers, and hence endorsed the criteria for the type of teacher the School Management Team wanted to fill a position in a primary school. What the participants are expressing is similar to what Xaba and Nhlapo (2014) found in their study, namely, that in the majority of SGBs, parent members are not adequately trained on their roles in the committee. The first time they hear about a position for a teacher in their school is when the position is being advertised without their approval. Nyembezi explained,

Because when they advertise these posts they say, they are looking for a female teacher . . . but now if we can look at this and change that, they can open up now, even the male teachers can do what? They can apply when the jobs appear...

Yolisa added,

We are never involved in the advertisement process we just come for shortlisting and interviews ...

Ngezile went on to say,

My brother principals want only mamas there in the schools, and I tell you, they can change our decision ... they do not favour men because they cannot control them. . .

Ngezile's argument shows that male principals in schools are not keen to employ males because they are seen as a threat to the principals' power and the patriarchal system in general given the gendered belief that women can be controlled while men cannot. This problematic notion is, of course, a result of the patriarchal gender order in these communities (see Ratele, 2015). In their respective studies of school leadership and governance, Bush and Glover (2016), Mncube and Mafora (2013) and Prinsloo (2016) all found that because of the power given to principals, they tend to overrule SGBs' decisions about the appointment of 
staff, and in Ngezile's case, the appointment of males in FP teaching. Principals and teachers in SGB committees tend to take advantage of parent-members' low level of policy understanding (Prinsloo, 2016), and this leads to corruption, nepotism, and to their personal preferences being employed.

In the school context, principals are regarded as upstanding members of their respective communities and as possessing superior knowledge. The knowledge and wisdom principals are perceived to possess allows them to override decisions of ordinary SGB members who are believed to have limited knowledge. Van Wyk's (2004) study of SGBs and experiences of South African educators recommends that SGB members should be intensively trained in the application of the Educators Employment Act of 1998 (Department of Basic Education, 2011a) and other relevant legislation. Bush and Glover (2016) agreed and suggested that empowering SGB members requires intense literacy and policy training.

After recognising the SGB members' unawareness of their roles in the employment of teachers, we conducted a workshop with all participants to familiarise them with the SASA and Educator Employment Act. We also discussed how social justice practices might look in their context. This was motivated by Moorosi's (2010) comment on how researchers should work towards social change and conscientisation of people at grassroots level regarding patriarchal practices that may obstruct the diversification of educational institutions.

Engaging with communities requires patience since the patriarchal norms and values are deeply embedded in their everyday lives (Ratele, 2015). Our participants indicated that a transition process would be challenging because of their deeply embedded beliefs regarding gender roles but also acknowledged the necessity of diversifying FP teaching through a fair and non-discriminatory process of employment.

In their reflections of the entire process of data generation and workshopping, the SGB members said,

Possibilities of transformation for me and my community will not be easy ... To trust a man with our children is not simple. . . seeing that it's my responsibility to diversify the school we will try to rethink our approach of employment in Foundation phase ... (Ngezile)

It is funny how we think we are protecting the communities we serve only to find we are the ones killing them. . . there should be changes in foundation phase $\mathrm{Mr}$. . . but I tell you it will not be simple... (Nyembezi)

I still say given that they (males) have all relevant qualification. . . they have my vote. (Nomi)

I support Nomi . . . change is good even if it's painful sometimes . . (Nozuko)

We need to focus on fair policy implementation; men are human too hey. . . we need to think of an easy approach to bring men in our school even if only a few. . (Yolisa) 
From these discussions, the SGB participants began the process of re-imagining how they could correctly interpret and implement policies that govern their schools. These SGB participants need to deconstruct their understanding of FP teaching not just as care work but as a respectable profession for all interested in it (Bhana, 2016; Mashiya et al., 2015; Warin, 2019) to promote diversity in early childhood education. One of the measures to prevent the (re)production of hegemonic cultural stereotypes of gender roles is for communities to continue to facilitate and engage in difficult and courageous conversations that dismantle deep-seated social realities (Ratele, 2015). The work to deconstruct problematic notions of FP teaching is broad and requires multi-dimensional and multisectoral interventions.

\section{Discussions and conclusion}

Ratele (2015) and Bhana (2016) recommended that for men to transform and develop various acceptable forms of masculinity that are pro-feminine and caring, deconstructive conversations at grassroots level are essential. This research engaged SGB members in the Eastern Cape province of South Africa concerning their role in the employment of male FP teachers in their primary schools. In this paper, we have shown that the SGB members in this study lean on the dominant and powerful discourses in their communities that are produced through a patriarchal gender order that dissociates men from early childhood education. The study further demonstrated how these parent-component members of SGBs had limited understanding of governing policies that could enable them to disrupt the normative practices.

The SGBs interactions and socialisation in hetero-patriarchal contexts that hold hegemonic masculinities as powerful justified their acceptance of unfair employment practices against men wishing to join FP teaching staff. However, their engagement in conversations and workshops in this study created conducive conditions for them to alter their gendered rationalisations regarding the employment of male teachers in early childhood education.

Even though not all the participants agreed on the inclusion of men in FP teaching, it is important to note that ongoing conversations to disrupt the normative perception of FP teaching as a feminine sphere have commenced. This study has produced encouraging results showing that possibilities for a changed education landscape exist in early childhood education, as well changed views on masculinities. hooks (2004) and Msiza (2020) have proposed that for communities to challenge patriarchy, they need to deconstruct normative constructions of masculinities. In working with communities to help alleviate inequality and discrimination in South Africa and prevent unequal distribution of labour based on gender, it is vital to debunk the notion of care work as feminine and construct it as a respectable profession for all interested in it. SGB members also need to diversify FP teaching through the employment of male teachers (Bhana, 2015, 2016; Ratele, 2015). To make this a possibility, in-depth comprehension of how hegemonic patriarchal discourses operate and are sustained should be created, so as to deconstruct problematic perceptions of femininity and masculinity (Ratele, 2016). 
This study, therefore, recommends that conversations on men and FP teaching with multistakeholder participants should continue. Research on other gatekeepers and parents is missing in the literature on the South African context. Thus, further research involving all educational stakeholders could provide an understanding of what a re-imagined and diverse FP teaching landscape could look like (Mills, 2004; Msiza, 2020). Such research could be useful in understanding teacher identity constructions in different educational bands and how they are perceived by different educational stakeholders. It could also lead to positive policy interpretation and implementation such that South African schools redress the injustices of their apartheid and colonial past and forge a path towards the achievement of the global sustainable development goals.

\section{References}

Barrett, M. J. (2005). Making (some) sense of feminist poststructuralism in environmental education research and practice. Canadian Journal of Environmental Education, 10(1), 79-93.

Basson, P., \& Mestry, R., 2019. Collaboration between school management teams and governing bodies in effectively managing public primary school finances. South African Journal of Education, 39(2), 1-11,

Bhana, D. (2016). Gender and Childhood Sexuality in Primary School. Springer.

Bhana, D., \& Moosa, S. (2016). Failing to attract males in foundation phase teaching: An issue of masculinities. Gender and Education, 28(1), 1-19.

Blaise, M. (2005). Playing it straight: Uncovering gender discourses in the early childhood classroom. Routledge.

Brownhill, S. (2015). Male role models in education-based settings (0-8): An English perspective. In S. Brownhill, J. Warin \& I. Wernersson (Eds.), Men, masculinities and teaching in early childhood education: International perspectives on gender and care (pp. 26-35). Routledge.

Bush, T., \& Glover, D. (2016). School leadership and management in South Africa: Findings from a systematic literature review. International Journal of Educational Management, 30(2), 211-231.

Butler, J. (1990). Gender trouble: Feminism and the subversion of identity. Routledge.

Cameron, C., Moss, P., \& Owen, C. (1999). Men in the nursery: Gender and caring work. Sage.

Connell, R. (2009). Gender: In world perspective. Polity. 
Crawley, S. L., \& Broad, K. L. (2008). The construction of sex and sexualities. In J. Holstein \& J. Gubrium (Eds.), Handbook of constructionist research (pp. 545-566). Guilford Press.

Creswell, J. W., \& Creswell, J. D. (2017). Research design: Qualitative, quantitative, and mixed methods approaches. Sage.

Cruickshank, V., Pedersen, S., Cooley, P. D., \& Hill, A. (2018). Towards a measure of gender-related challenges faced by male primary teachers. Australian Journal of Education, 62(1), 49-60.

Davies, B., \& Gannon, S. (2005). Feminist/Poststructuralism. In C. Lewin \& B. Somekh (Eds)., Research methods in the social sciences. (pp. 318-325). Sage.

Department of Basic Education, Republic of South Africa. (2011a). Employment of Educators Act 76 of 1998. Government Gazette No 34620, Vol 555. Government Printer.

Department of Basic Education, Republic of South Africa. (2011b). South African Schools Act 84 of 1996. Government Gazette, No 34620, Vol 555. Government Printer.

De Vos, A., Strydom, H., Fouché, C. B., \& Delport, C. (2014). Research at grass roots: A primer for the social science and human professions. Van Schaik Publishers.

Foucault, M. (1980). Power/knowledge: Selected interviews and other writings, 1972-1977 by Michel Foucault. In C. Gordon (Ed.), (C. Gordon., L. Mepham \& K. Soper, Trans.). Pantheon Books.

Jackson, A.Y. (2001). Multiple Annies: Feminist post-structural theory and the making of a teacher. Journal of Teacher Education, 52(5), 386-397.

Jewkes, R., Morrell, R., Hearn, J., Lundqvist, E., Blackbeard, D., Lindegger, G., Quayle, M., Sikweyiya, Y. \& Gottzén, L. (2015). Hegemonic masculinity: Combining theory and practice in gender interventions. Culture, Health \& Sexuality, 17(2), 112-127.

hooks, B. (2004). We real cool: Black men and masculinity. Psychology Press.

Kagola, O., \& Khau, M. (2020). Using collages to change school governing body perceptions of male Foundation Phase teachers. Educational Research for Social Change, 9(2), 65-80.

Lather, P. (1991). Getting smart: Feminist research and pedagogy with/in the post-modern. Routledge.

Mashiya, N., Kok, L., Luthuli, N., Xulu, S., \& Mtshali, Z. (2015). Foregrounding the gender divides in early childhood teacher education: A case of South Africa. Journal of Social Sciences, 42(3), 259-265. 
Mayeza, E. (2018). 'Charmer boys' and 'cream girls': How primary school children construct themselves as heterosexual subjects through football. Discourse: Studies in the Cultural Politics of Education, 39(1), 128-141.

McCormack, O., \& Brownhill, S. (2014). 'Moving away from the caring': Exploring the views of in-service and pre-service male teachers about the concept of the male teacher as a role model at an early childhood and post-primary level. International Journal of Academic Research in Education and Review, 2(4), 82-96.

Mfecane, S. (2016). "Ndiyindoda" [I am a man]: Theorising Xhosa masculinity. Anthropology Southern Africa, 39(3), 204-214.

Mills, M. (2004). Male teachers, homophobia, misogyny and teacher education. Teaching Education, 15(1), 27-39.

Mncube, V. S. (2007). Social justice, policy and parents' understanding of their voice in school governing bodies in South Africa. Journal of Educational Administration and History, 39(2), 129-143.

Mncube, V., \& Mafora, P. (2013). School governing bodies in strengthening democracy and social justice: Parents as partners? The Anthropologist, 15(1), 13-23.

Moorosi, P. (2010). South African female principals' career paths: Understanding the gender gap in secondary school management. Educational Management Administration \& Leadership, 38(5), 547-562.

Moosa, S., \& Bhana, D. (2017). Men managing, not teaching Foundation Phase: Teachers, masculinity and the early years of primary schooling. Educational Review, 69(3), $366-387$.

Moosa, S., \& Bhana, D. (2018). 'They won't take you as a man, as a real man': Why men can't teach young children in Foundation Phase. International Journal of Inclusive Education, 22(6), 577-593.

Moosa, S., \& Bhana, D. (2020). Men teaching young children: "You can never be too sure what their intentions might be." Oxford Review of Education, 46(2), 169-184.

Morrell, R., Jewkes, R., \& Lindegger, G. (2012). Hegemonic masculinity/masculinities in South Africa: Culture, power, and gender politics. Men and Masculinities, 15(1), $11-30$.

Morrell, R. (2019). Vehicle for Southern African knowledge? Men and masculinities and research from South Africa. Men and Masculinities, 22(1), 34-43.

Msibi, T. (2009). Not crossing the line: Masculinities and homophobic violence in South Africa. Agenda, 23(80), 50-54. 
Msiza, V. (2019). 'You are a male teacher, but you have a woman's heart': Foundation Phase teachers negotiating identities in South Africa. Education, 3(13), 1-10.

Msiza, V. (2020). 'I don't like them coming to me and saying hey, I like you': Male teachers in relegated positions of masculinity. Agenda, 34(2), 86-93.

Mutekwe, E., 2020. Embracing equitable learning in managing the physical and financial resources in South-African-schools: A social justice perspective. South African Journal of Education, 40(4), 1-11.

Ntombana, L. (2011). "Should Xhosa male initiation be abolished?" International Journal of Cultural Studies, 14(6), 631-640.

Osgood, J. (2012). Narratives from the nursery: Negotiating professional identities in early childhood. Routledge.

Pitsoe, V., \& Letseka, M. (2013). Foucault's discourse and power: Implications for instructionist classroom management. Open Journal of Philosophy, 3(1), 23-28.

Prinsloo, S. (2016). The dual role of the principal as employee of the Department of Education and ex officio member of the governing body. South African Journal of Education, 36(2), 1-9.

Ratele, K. (2015). Working through resistance in engaging boys and men towards gender equality and progressive masculinities. Culture, Health \& Sexuality, 17(2): 144-158.

Ratele, K. (2016). Liberating masculinities. Human Science Research Council Press.

Ratele, K., Shefer, T., \& Clowes, L. (2012). Talking South African fathers: A critical examination of men's constructions and experiences of fatherhood and fatherlessness. South African Journal of Psychology, 42(4), 553-563.

Skelton, C. (2003). Male primary teachers and perceptions of masculinity. Educational Review, 55(2), 195-209.

Skelton, C. (2012). Men teachers and the "feminised" primary school: A review of the literature. Educational Review, 64(1), 1-19.

Smit, M. H., \& Oosthuizen, I. J. (2011). Improving school governance through participative democracy and the law. South African Journal of Education, 31(1), 55-73.

St. Pierre, E. (2000). Post-structural feminism in education: An overview. Qualitative Studies in Education, 13(5), 477-515.

Taylor, P. C., \& Medina, M. (2011). Educational research paradigms: From positivism to pluralism. College Research Journal, 1(1), 1-16. 
Tenge, S. (2006). Xhosa teenage boys' experience during the period prior to circumcision ritual in East London in the Eastern Cape Province (Unpublished doctoral dissertation). University of South Africa, Pretoria, RSA.

Van Wyk, N. (2004). School governing bodies: The experiences of South African educators. South African Journal of Education, 24(1), 49-54.

Warin, J. (2019): Conceptualising the value of male practitioners in early childhood education and care: Gender balance or gender flexibility. Gender and Education, 31(1), 293-308.

Warin, J., \& Adriany, A. (2017) Gender flexible pedagogy in early childhood education. Journal of Gender Studies, 26(4), 375-386.

Weedon, C. (1997). Feminist practice and poststructuralist theory. Blackwell.

Xaba, M. I., \& Nhlapo, V. A. (2014). Principals' views on challenges of their school governance roles. Africa Education Review, 11(3), 424-444.

Xu, Y., \& Waniganayake, M. (2018). An exploratory study of gender and male teachers in early childhood education and care centres in China. Compare. A Journal of Comparative and International Education, 48(4), 518-534. 